\title{
Kahramanmaraş-Elmalar Yeşil Kuşak Ek-3 Plantasyon Sahasında Görülen Biyotik ve Abiyotik Zararlıların Tespiti
}

\author{
Bülent LAZ ${ }^{-}$(D) , Emre BABUR ${ }^{1}$ (D), Durdu Mehmet AKPINAR ${ }^{2}$ iD, Sakine Serap AVGIN ${ }^{3}$ (D) \\ ${ }^{1}$ Kahramanmaraş Sütçü imam Üniversitesi, Orman Fakültesi Orman Mühendisliğ̈i Bölümü, Kahramanmaraş, ${ }^{2}$ Kahramanmaraş Orman Bölge \\ Müdürlüğü, Merkez İşletme Şefliği, Kahramanmaraş, ${ }^{3}$ Kahramanmaraş Sütçü imam Üniversitesi, Eğitim Fakültesi, Matematik ve Fen \\ Bilimleri Ĕ̆itimi Bölümü, Kahramanmaraş \\ 凶: bulentlaz@ksu.edu.tr
}

\section{ÖZET}

Kahramanmaraş İlinde tehlikeli boyutlara ulaşan çevre ve hava kirliliği problemlerini önlemenin yanında rekreatif amaçlı kent ormanları tesisi de düşünülerek Kahramanmaraş Orman Bölge Müdürlüğü tarafından 2003-2004 yıllarında Yeşil kuşak Ağaçlandırma Projesi kapsamında kentin çevresinde ağaçlandırmalar yapılmıştır. Bu ağaçlandırma çalışmalarından kent merkezine yakın olan 1675 ha lık sahada araştırmamı gerçekleştirilmiştir. Ağaçlandırma sahasında Pinus brutia, Pinus pinea, Cupressus sempervirens, Prunus mahalep, Amygdalus sp, Pyrus elaegnifolia ve yabancı orijinli Pinus brutia var. elderica türleri kullanılmıştır. Kullanılan türlerden yabancı orijinli Pinus brutia var. elderica da oldukça fazla miktarda form bozuklukları ve kurumalar olduğu gözlemlenmiştir. $\mathrm{Bu}$ türde diğer türlere göre daha fazla böcek ve mantar hastalık zararlıları tespit edilmiştir. Bu zararlı böcekler arasında Thaumetopha pityocampa-wilkinsoni (Lep.), Rhyaciona buoliana (Lep.), Ortotomicus erosus (Scolytidea, Col.), Hylurgus ligniperda (Scolytidea, Col.), Hylurgus micklitzi (Scolytidea, Col.), Tomicus piniperda (Scolytidea, Col.),, Tomicus destruens (Scolytidea, Col.), Ips sexdentatus (Scolytidea, Col.), Leucaspis pusilla (CoccoideaHem.) gibi zararlı böceklerle, Melampsora piniturqua, Diplodea pinea gibi mantar hastalıkları tespit edilmiştir. Ağaç türlerinin genelinde kurumaların gözlemlenmesi sonucunda yetişme ortamı faktörlerinden iklim, anakaya ve toprak özellikleri incelenmiştir. Verimsiz anakaya ve toprak koşullarının olumsuz iklim koşulları ile birleşmesi sonucunda bu alandaki yetişme ortamı koşullarına uyum sağlayamayan ağaçların zayıf düştüğü ve sonunda kurumaların görüldüğü tespit edilmiştir. $\mathrm{Bu}$ çalışmada ileride yapılacak ağaçlandırmalarda sekonder zararlılar olan kabuk böceği ve mantar zararlarının en aza indirilmesi için yetişme ortamı faktörlerinin de göz önünde bulundurularak uygun türlerin seçimi ekolojik ve ekonomik açıdan oldukça önemli olduğu sonucuna varılmıştır.

\section{DOI:10.18016/ksutarimdoga.vi.426042}

\author{
Makale Tarihçesi \\ Geliş Tarihi: 23.05.2018
}

Kabul Tarihi : 04.07.2018

\section{Anahtar Kelimeler}

Yeşil kuşak ağaçlandırmaları, Böcek ve mantar zararı, yetişme ortamı koşulları, toprak sağlığı

\section{Araştırma Makalesi}

\section{Determination of Biotic and Abiotic Plant Diseases in Green Belt Afforestation of Kahramanmaraş- Elmalar}

\section{ABSTRACT}

The afforestation was carried out around the city in order to prevent hazardous environmental and air pollution problems and with the purpose of recreational urban forests facility for public health in Green Belt Afforestation Project in 2003-2004 supported by Kahramanmaras Regional Directorate of Forestry. Our study was performed in one of the Green Belt Afforestation Fields (1675 ha.) area near the city center. In the study Pinus brutia, Pinus pinea, Cupressus sempervirens, Prunus mahalep, Amygdalus sp, Pyrus elaegnifolia and the alien origin Pinus brutia var. elderica plant species were used. A large quantity of disorders and dryness in the alien origin (Pinus brutia var. Elderica) were observed during the study. Greater number

\section{Article History}

Received : 23.05.2018

Accepted : 04.07.2018

\section{Keywords}

Green belt afforestation, biotic and abiotic diseases, site, soil health

\section{Research Article}


of insect and fungal diseases were detected on this species than others. The insects including Thaumetopha pityocampa-wilkinsoni (Lep.), Rhyaciona buoliana (Lep.), Ortotomicus erosus (Scolytidea, Col.), Hylurgus ligniperda (Scolytidea, Col.), Hylurgus micklitzi (Scolytidea, Col.), Tomicus piniperda (Scolytidea, Col.), Tomicus destruens (Scolytidea, Col.), Ips sexdentatus (Scolytidea, Col.), Leucaspis pusilla (Coccoidea-Hem.) and some fungal diseases such as Melampsora piniturqua, Diplodea pinea were detected. As a result of observing the form disorder within the whole tree species, some factors such as climate, bedrock and soil characteristics were examined. As a result of the combination of inefficient bedrock and soil conditions with adverse climatic conditions, it has been determined that trees that cannot be well adapted to the conditions of the site were weakened and finally dried. Consequently, the selection of the suitable species is very important in terms of ecological and economic aspects considering the site factors in order to minimize the diseases of insect and fungi in the future afforestation.

To cite: Laz B, Babür E, Akpınar DM, Avgın SS 2018. Kahramanmaraş-Elmalar Yeşil Kuşak Ek-3 Plantasyon Sahasında Görülen Biyotik ve Abiyotik Zararlıların Tespiti. KSÜ Tar Doğa Derg 21(6) : 926-935, DOI:10.18016/ksutarimdoga.vi.426042

\section{GİRIŞ}

Günümüzde artan çevre, su, toprak ve hava kirliliği, karbon emisyonları gibi sorunların en etkili çözümü olarak ağaçlandırma çalışmaları ile orman alanlarının arttırılmasıdır. Bunun yanında küresel ısınmaya bağlı iklim değişimlerini önlemek, çölleşme ve erozyona engel olmak amacıyla farklı boyutlara evrilen çevre sorunları ile başa çıkmada ormanların giderek artan fonksiyonel özellikleri dikkate alınarak ormanların verimli hale getirilmesinin yanında yeni orman alanlarının kazanılması da ekolojik ve ekonomik açıdan büyük önem taşımaktadır. Ormanlar ayrıca insanların içme ve kullanmak amacıyla depoladıkları suyun kaliteli ve yeterli miktarda olmasinı sağlamaktadır. Su toplama havzalarında yapılan ağaçlandırma çalışmaları toprakların akarsular ile taşınmasını önleyerek barajların ömrünün uzamasına, enerji üretimi ve içme-kullanma-arazi sulaması sürelerini de yüzyıllarla ifade edilecek şekilde uzatabilmektedir. Bozulan doğal dengenin yeniden kurulması ve bu su rejiminin düzenlenmesi ancak "ağaçlandırmalarla" mümkündür.

Günümüzde yaşam olanaklarının ve imkânların daha iyi olduğu düşünülen Büyük şehirlerde nüfus artışları oldukça yüksek miktarlara ulaşmıştır. Artan nüfus beraberinde tehlikeli boyutlara ulaşan çevre sorunlarının doğmasına neden olmuştur. Ayrıca bu şehirlerde insanların rahat ve huzurlu yaşayabilmesi için kişi başına düşen yeşil alan miktarını artırmak, topluma rekreatif amaçlı imkânlar sağlamak, toprak ve bitki arasında bozulan tabii dengeyi kurmak, yerleşim yerlerini sel ve taşkın zararlarından korumak ve karbon stokunu arttırmak gibi ihtiyaçların oluşması söz konusudur. Bütün bu ihtiyaçların giderilmesi ve sürdürülebilir çevre koşullarının sağlanması için Orman Genel Müdürlüğü tarafından (bilhassa son 10-20 yıldır) büyük şehirlere yakın stratejik alanlarda Yeşil Kuşak Projeleri uygulamalarına gerek duyulmuştur (Anonim, 1992).

Ağaçlandırmaya konu olan sahalar, genelde üzerinde daha önceden orman formasyonu bulunmayan ya da antropojen etkilerle orman örtüsü tahrip edilmiş, toprak ve diğer ekolojik koşullar bakımından problemli yerlerdir. Serpantinit anakayasının bulunduğu alanlar ise bu problemli sahalarm en önemlilerinden birisidir. Serpantinit anakayası yapısı bakımından zor ayrışmasından dolayı üzerinde genellikle sığ ve taşlı topraklar meydana gelmektedir. Ayrıca serpantinit anakayası minerolojik özellikleri bakımından toprağa fazla miktarda $\mathrm{Mg}$ kazandırmaktadır. $\mathrm{Bu}$ ise bitkilerin yetişmesi, gelişmesi açısından hiç de uygun olmayan bir durumdur. Serpantin probleminin edafik faktör kısmı, kimyasal, fiziksel ve biyotik bileşenleri ile çok yönlüdür. Bitkiler üzerindeki en etkili bileşen ise kimyasal olanıdır (Kruckeberg, 1985). Serpantinli topraklar düşük $\mathrm{Ca}: \mathrm{Mg}$ oranı ile karakterize edilmektedir. $\mathrm{Bu}$ alanlarda $\mathrm{Ca}$ konsantrasyonu, civardaki diğer alanlara kıyasla çok düşüktür. Ayrıca serpantinit toprakları $\mathrm{Ni}$, Co, Cr gibi ağır metaller bakımından zengindir ve yüksek oranda $\mathrm{Mg}$ ve $\mathrm{Fe}$ içerirken, $\mathrm{Ca}, \mathrm{K}, \mathrm{N}$ ve $\mathrm{P}$ gibi bazı ana besinler açısından da fakirdir (Gordon ve Lipman, 1926; Vlamis ve Jenny, 1948; Walker, 1954; Proctor ve Woodell, 1975; Brooks, 1987). Serpantinit anakayaları üzerinde oluşan topraklarda bulunan bu elementler birçok bitki için zehir etkisi oluşturur. Serpantinli topraklarda düşük konsantrasyonda bulunan $\mathrm{Ca}$, serpantin sendromunun başlica sebebidir (Vlamis ve Jenny, 1948). Yüksek $\mathrm{Mg}$ oranı da bu problemi daha da karmaşıklaştırmıştır. Bu hipotez birçok çalışma ile de desteklenmiştir (Walker, 1948; Vlamis, 1949; 
Kruckeberg, 1954; Walker ve ark., 1955). Ayrica, serpantinit topraklarin verimsiz ve su tutma kapasitesinin düşük olması, bu toprakların organik materyalinin az ve fiziksel yapısının zayıf olmasından kaynaklanmaktadır (Brooks, 1987). Serpantinit topraklarda toz ve kil miktarı bakımından çok düşük seviyededir (Brady ve ark., 2005). Bu toprakların fiziksel şartları birçok bitki türü için uygun değildir, bu durum serpantinit alanlarda vejetasyon açısından çok seyrek olan, flora açısından ise çok fazla farklılık gösteren bir tablo ortaya koymuştur (Baker ve ark., 1992; Batianoff ve Singh, 2001). Bu alanlar üzerinde yaşayan bitkiler, olumsuz edafik faktörlere ve yüksek konsantrasyondaki ağır metaller gibi ekstrem koşullara uyum sağlamalıdır (Kruckeberg, 1985; Avcı, 2005).

Serpantinit kayaçların bulunduğu alanlar endemik bitkilerce zengindir ve bu durum da "jeolojik izolasyon" olarak açıklanmaktadır. "Jeolojik adalar" veya "edafik adalar" olarak serpantin habitatları diğer toprak çeşitleri arasında yerini almaktadır. Ekstrem edafik koşullara genetik açıdan adapte olmuş kimi bitkilerin bu topraklar üzerinde yayıldığı belirtilmektedir (Kantarcı, 1987; Kruckeberg ve ark., 1999; Reeves ve ark., 1999; Adıgüzel ve Reeves, 2002). Serpantinik anakayalarının bulunduğu alanlar üzerinde yaşayan bitkilerin daha çok sert yapraklılar (sklerofil) bakımından zengin bodur bitki örtüsü, tür sayısının az ancak bu koşullara uyum sağlamış endemik bitkilerce zengin bir yapı oluşturmaktadır (Kruckeberg, 1954).

Kahramanmaraş ilinin bulunduğu Doğu Akdeniz'in doğusu arazi bozulması ve çölleşme riskinin en yüksek olduğu bölgelerden biridir (Şahin ve Avcıŏlu, 2017). Kahramanmaraş Türkiye'de ağaçlandırma çalışmalarının en fazla yapıldığı illerin başında gelmektedir. 2004-2005 yıllarında KahramanmaraşGaziantep Karayolu üzerinde 675 ha lik alanda farklı türler kullanılarak ağaçlandırma gerçekleştirilmiştir. Sahaya hızlı gelişen ve kuraklığa dayanıklı olduğu bilinen yabancı orijinli Pinus brutia var. elderica, yerel orijinli Pinus brutia, Pinus pinea, Cupressus sempervirens, Prunus mahalep, Pyrus communis, Pyrus elaegnifolia, Amygdalus sp. türleri dikilmiştir. Plantasyon sahasinda kullanılan Pinus brutia var. elderica kuraklığa dayanıklı olarak bilinen bir ağaç türüdür. $\mathrm{Bu}$ yüzden dünya da pek çok ülkede kuraklığa dayanıklı olan bu tür ağaçlandırma sahalarında kullanılmıştır. Amerika Birleşik Devletleri'nde ağaçlandırmada kullanılan Pinus brutia var. elderica, afid türlerine ve bazı akar türlerine karşı hassas olduğu, sürgünlerde zarar yapan Ryaciona neomexicana (Lep.), Eurytomidae familyasından yaban arılarmın, yaprak yiyen bazı kelebek türleri ve bazı kabuk böcekleri tarafından zarara uğratıldığı ayrıca Phymatotrichopsis omnivora, Diplodia pinea gibi mantar zararlılarıla karşılaştıkları rapor edilmiştir (Shine-Ring, 2010).
Kahramanmaraş kent merkezine yakın plantasyon sahasında (Ek-3) görülen zararlı böcek ve hastalıkların belirlenmesi amacıyla bu çalışma ele alınmıştır.

\section{MATERYAL ve METOT}

\section{Çalışma Sahasının Genel Özellikleri}

Çalışmanın yapıldığg alan Kahramanmaraş ilinin yaklaşık $20 \mathrm{~km}$ doğusundaki Elmalar Orman İşletme Şefliği sınırları içerisinde kalmaktadır. Yeşil kuşak ek3 ağaçlandırma çalışması adı altında 675 ha lık alanda bu çalışma gerçekleştirilmiştir. Plantasyon sahası 550$800 \mathrm{~m}$ rakımlar arasında, serpantinit anakayası üzerinde bulunmaktadır. Akdeniz iklimi ile Karasal iklim geçiş alanı üzerinde bulunan ağaçlandırma alanında genellikle sıcak ve ılıman iklim görülmektedir. Köppen-Geiger iklim sinıflandırmasına göre Csa olarak adlandırılabilir. Sahanın yıllık ortalama sicaklığ $16.1^{\circ} \mathrm{C}$ dir. Temmuz ayı $28.1^{\circ} \mathrm{C}$ sicaklıkla yılın en sicak ayı iken Ocak ayında ortalama sıcaklık $4.1{ }^{\circ} \mathrm{C}$ ile en soğuk aydır. Yıllık ortalama yağış miktarı $638 \mathrm{~mm}$ dir. Temmuz ayı $2 \mathrm{~mm}$ lik yağışla yılın en kurak ayıdır. En fazla yağış miktarı ise ortalama $118 \mathrm{~mm}$ ile Ocak ayında görülmektedir. Toprak derinliğinin $30-50 \mathrm{~cm}$, fizyolojik derinliğin 60-120 cm arasında değişken olduğu bir alandır. Arazi gözlemlerinde anakayanın yer yer yüzeye yakın olduğu, toprak yüzeyinin oldukça kuru ve organik materyal bakımından çıplak olan verimsiz alanlardan olduğu gözlemlenmiştir.

\section{Arazi Çalışmaları}

Çalışma alanında biyotik ve abiyotik zararlıların tespit edilebilmesi için tür bazında alan üzerinde böcek ve mantar zararına uğramış ağaçların yoğun bulunduğu noktalardan dal, kabuk, yaprak örnekleri alınarak böcek ve mantar teşhisleri yapılmıştır. Bununla birlikte, araştırma sahasındaki zararlı böcek faunasinı ortaya koymak amaciyla sahaya yerleştirilen feromon tuzaklarına gelen böcekler 15 günlük periyotlarla toplanmış ve elde edilen kabuk böceklerinin teşhisi Isparta Süleyman Demirel Üniversitesi, Orman Fakültesi, Entomoloji ve Koruma Laboratuvarında yapılmıştır. Ayrıca bu noktalarda sekonder zararlılar olan biyotik zararlıları bu alanlar için cazip kılan etkinin ne olduğunu anlamak için yetişme ortamının ve toprak özelliklerinin incelenmesi için rast gele yöntem ile (kurumaların yoğun olduğu yerlerden) belirlenen noktalardan 5 adet toprak çukuru ekskavatör kullanılarak açılmıştır. Açılan toprak çukurlarından üst $\left(0^{-}-20 \mathrm{~cm}\right)$ ve alt $(20-40 \mathrm{~cm})$ derinlik kademelerinden bozulmamış (yaklaşık $1 \mathrm{~kg}$ kadar) toprak örnekleri alınmıştır (Şekil 1). Alınan toprak örneklerinin fiziksel özellikleri KSÜ Orman Fakültesi Toprak ve Ekoloji Laboratuvarında, kimyasal özellikleri ise Eskişehir Ormancılık Araştırma Enstitüsü Toprak Laboratuvarında analiz 
edilmiştir. Çalışma sahasının anakaya teşhisinin yapılması için rast gele yöntemler ile toprak numunelerinin alındığ örnekleri toplanmış ve KSÜ Jeoloji Mühendisliği Bölümünde teşhis ettirilmiştir.

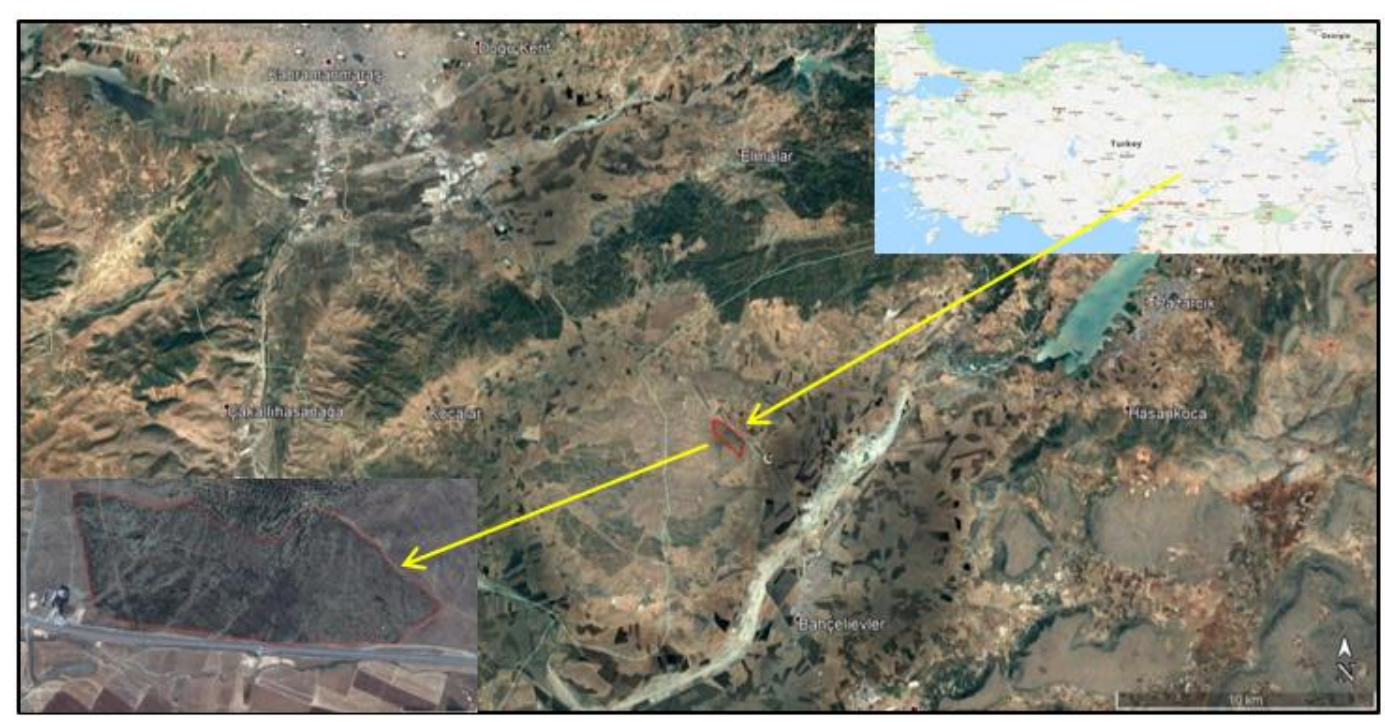

Şekil 1. Çalışma sahasının bulunduğu konum

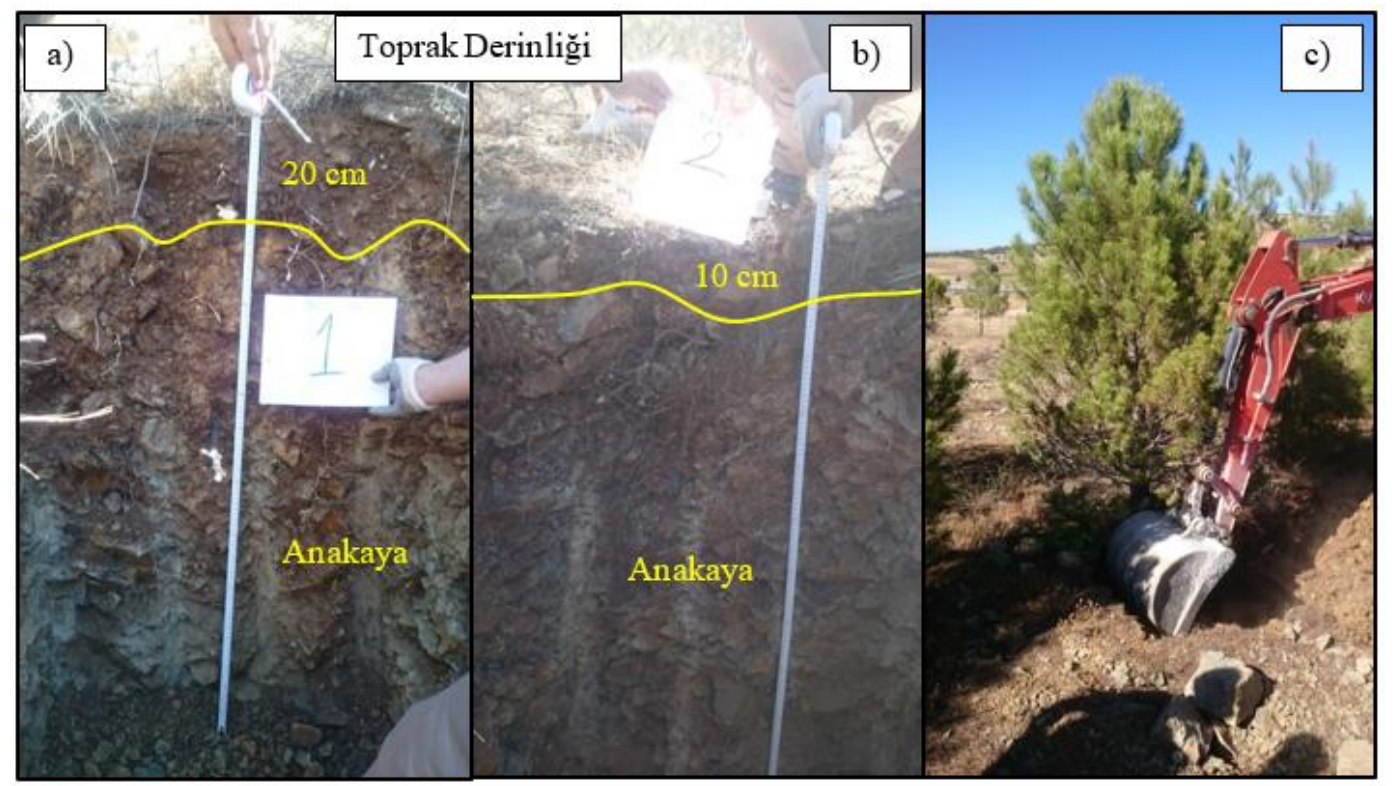

Şekil 2a ve 2b. Toprak numunelerinin alınması

\section{Laboratuvar Çalışmaları}

Açılan toprak çukurlarından alınan toprak örneklerinin fiziksel ve kimyasal toprak özelliklerini belirlemek için hava kurusu hale gelinceye dek kurutulup, taş ve kökleri ayrılarak porselen havanda ögütülür ve $2 \mathrm{~mm}$ 'lik elekten geçirilerek, numuneler polietilen plastik poşetlerde saklanır. Alınan toprak örneklerinde; nem içeriği (gravimetrik yöntem), tane çapı (Tekstür hidrometre (Bouyoucus, 1951)), organik karbon (yaş yakma (Walkley, 1947)), EC 1/5 toprak su çözeltisi (Janzen, 2004), pH 1/2.5 toprak su çözeltisi (Janzen, 2004) cam elektrotu metotları ile belirlenmiştir.

Toplam makro ve mikro besin elementlerinden yarayışlı fosfor (P) Spectronic 20D cihazında değiştirilmiş Bray ve Kurtz yöntemine göre (Ülgen ve Ateşalp 1972), $\mathrm{K}^{+}$ve $\mathrm{Na}^{+}$Jenway PFP 7 flame photometer cihazında, $\mathrm{Ca}^{++}$ve $\mathrm{Mg}^{++}$Perkin-Elmer 3110 atomic absorption spectrometer cihazında ölçülmüştür.

\section{BULGULAR ve TARTISSMA}

Abiyotik Bulgular:

Ağaçlandırma Sahası Toprak Özellikleri

Ağaçlandırma alanından alınmış toprak numunelerinin $(0-10 \mathrm{~cm}$ ve $10-20 \mathrm{~cm})$ fiziksel ve kimyasal özelliklerinin belirlenmesi sonucunda kumlu killi balçık türündeki araştırma sahası toprakları hafif 
alkali reaksiyona sahiptir. Ortalama kum, toz ve kil oranları bakımindan sirasıla \%60.57, \%15.04 ve $\% 24.40$ dir. Toprak reaksiyonu $(\mathrm{pH})$ değeri 7.22-7.60 arasında değişmektedir. Ortalama ph değeri 7.44 olması hafif alkali sinıfinda olduğunu bu $\mathrm{pH}$ derecelerinde bitki besin elementlerinin bitkiler tarafından alımının azalacağı anlamına gelmektedir (Çizelge 1). Toprak organik karbonu bakımından da oldukça fakir olan toprakların ortalama karbon yüzdesi $\% \quad 0.81$ dir. $\mathrm{Bu}$ değer alanda organik materyalin az olduğunu ve ağaçların organik besin kaynağının yetersiz olduğunu göstermektedir.

Bitki besin elementlerinden azot $(\% \mathrm{~N})$, kalsiyum (C $\mathrm{ppm}$ ), magnezyum ( $\mathrm{Mg} \mathrm{ppm})$, potasyum ( $\mathrm{K} \mathrm{ppm}$ ), sodyum (Na) ve fosfor (ppm) değerleri analiz edilmiştir. Bu analizler sonucunda K (166.30 ppm), N (\%0.12), $\mathrm{Na}(17.80 \mathrm{ppm})$ ve $\mathrm{Ca}(2033.20 \mathrm{ppm})$ bakımından yeterli seviyede bulunmaktadır. Buna karşın Mg miktarı oldukça fazla (1292.20 ppm) ve P miktarı (3.82 ppm) oldukça azdır (Çizelge 1).

Çizelge 1. Toprak numunelerinin bazı fiziksel ve kimyasal özelliklerinin ortalama değerleri

\begin{tabular}{|c|c|c|c|c|c|c|c|c|c|c|c|}
\hline Toprak no & Kum \% & Kil \% & Toz \% & $\mathrm{pH}$ & $\begin{array}{l}\text { OC } \\
(\%)\end{array}$ & N (\%) & $\begin{array}{l}\mathrm{Ca} \\
(\mathrm{ppm})\end{array}$ & $\begin{array}{l}\mathrm{Mg} \\
(\mathrm{ppm})\end{array}$ & $\begin{array}{l}\text { K } \\
(\mathrm{ppm})\end{array}$ & $\begin{array}{l}\mathrm{Na} \\
(\mathrm{ppm})\end{array}$ & $P(p p m)$ \\
\hline 1 & 67.82 & 14.60 & 17.57 & 7.60 & 0.750 & 0.1 & 2479 & 1218 & 140 & 15 & 4.7 \\
\hline 2 & 42.83 & 42.00 & 15.17 & 7.40 & 1.537 & 0.17 & 2799 & 1336 & 309 & 17 & 4.17 \\
\hline 3 & 51.92 & 37.36 & 10.72 & 7.47 & 0.678 & 0.11 & 1323 & 1504 & 62 & 23 & 3.38 \\
\hline 4 & 64.46 & 18.32 & 17.22 & 7.22 & 1.823 & 0.16 & 3098 & 1211 & 342 & 18 & 4.68 \\
\hline 5 & 54.75 & 32.18 & 13.08 & 7.35 & 0.714 & 0.1 & 2234 & 1257 & 306 & 24 & 3.32 \\
\hline 6 & 56.96 & 28.85 & 14.19 & 7.43 & 0.499 & 0.1 & 1157 & 1173 & 99 & 19 & 2.54 \\
\hline 7 & 60.19 & 25.34 & 14.47 & 7.36 & 0.642 & 0.1 & 2297 & 1212 & 116 & 11 & 3.13 \\
\hline 8 & 73.74 & 6.10 & 20.16 & 7.51 & 1.108 & 0.13 & 2529 & 1176 & 145 & 14 & 8.16 \\
\hline 9 & 71.98 & 23.44 & 4.58 & 7.55 & 0.320 & 0.13 & 1798 & 1359 & 81 & 18 & 2.23 \\
\hline 10 & 60.99 & 15.79 & 23.21 & 7.54 & 0.034 & 0.08 & 618 & 1476 & 63 & 19 & 1.92 \\
\hline Ortalama & 60.57 & 24.40 & 15.04 & 7.44 & 0.81 & 0.12 & 2033.20 & 1292.20 & 166.30 & 17.80 & 3.82 \\
\hline
\end{tabular}

OC: organik karbon, N: toplam azot, Ca: kalsiyum, Mg: magnezyum, K:potasyum,

$\mathrm{Na}$ : sodyum, $\mathrm{P}$ : fosfor

\section{Biyotik Bulgular:}

\section{Sahada görülen böcek zararları:}

\section{Yapraklarda Zarar Yapan Böcekler:}

Cam Kese Böceği (Thaumetopha pityocampawilkinsoni): Çam Kese Böceği Lepidoptera takımının Thaumetopoeidea familyasındandır. $\mathrm{Bu}$ böceğin larvaları ağaçların ibrelerini yiyerek zarar verirler. Miktarı az olursa yalnız yuvalarının civarında bulunan ibreler zarar görür. Kitle halinde ürediklerinde ağaçları ve meşcereleri tamamen çıplak hale getirirler. $\mathrm{Bu}$ türe genellikle güney bakılarda edafik faktörlerin zayıf olduğu topraklar üzerinde bulunan, herhangi bir sebeple açılmış, seyrekleşmiş çam meşcerelerinde ve makiler içerisinde bulunan çamlarda bu zararliya fazla rastlanır. Buna karşın kuzey bakıdaki derin ve nemli topraklar içeren sağlıklı yetişme ortamı koşullarında epidemi oluşturmamaktadır (Çanakçıŏglu ve Mol, 1998). Araştırma sahasında her yıl çam kese böceği zararı görülmüştür.

Sürgün Bükücüsü (Rhyaciona buoliana): Sürgün bükücüsü Lepidoptera takımının Tortricidae familyasındandır. Türkiye'de çam ağaçlarının en zararlı böceklerinden biridir. Larvalar tomurcukların iç kısımlarını oyarak tomurcukların ya kurumasına ya da postacı boynuzu denilen anormal bir oluşuma sebep olur. Bu durum yan sürgünün ana sürgünün yerini almasıyla gerçekleşir. Fidanlarda bu olay görüldüğünde fidanın tepe sürgünleri kuruduğundan fidanın değiştirilmesi gerekmektedir. Böcek epidemi yaptığında tüm tomurcuklar zarar görebilir ve ağaç çalı formu şeklini alabilir (URL 1). Araştırma sahasında bu böceğin geçmişte yaptığı zararlara rastlanmaktadır.

Çam Yaprak Kabuklu Biti (Leucaspis pusilla): Çam yaprak kabuklubiti Hemiptera takımının Coccidae familyasındandır. Çoğunlukla ibrelerin dip kısımlarında ya da iki ibrenin iç yüzeylerinde yerleşerek zarar oluştururlar. Böceğin beslendiği kısımlarda sarı renkli lekeler oluşturması tipiktir. İlerleyen zamanlarda sarı lekeler kahverengine dönüşür ve ibreler dökülmesine sebep olur. Epidemi yaptığında ağaçların ölümüne sebep olur. Ülkemizde Cedrus libani, Pinus brutia, Pinus pinea, Pinus sylvestris, Pinus halepensis, Pinus nigra üzerinde bulunduğu bildirilmiştir. Araştırma alanında bu böceğe yoğun şekilde rastlanmaktadır (Çanakçıŏglu ve Mol, 1998, Yaşar ve Küçükçakal, 2013).

\section{Kabukta Zarar Yapan Böcekler:}

Akdeniz Cam Kubuk böceği (Orthotomicus erosus): Akdeniz Çam Kubuk böceği Coloptera takımının Scolytidae familyasındandır. Başta kızılçam olmak üzere tüm çam türlerinde zarar yapar. O. erosus, 
Akdeniz ikliminin görüldüğü tüm alanlarda çam meşcerelerinin en önemli zararlı böceklerinden biridir. $\mathrm{Bu}$ tür sekonder zararlı bir böcektir. Kış yağışlarının az olduğu, llık ve kurak geçen kışların birbirini takip ettiği, isteklerine uygun olmayan yetişme ortaminda yetiştirilmeye çalışıldığında, sığ ve kumlu toprakların olduğu yerlerde, kar kırması ile kurutucu rüzgârların etkisi altında kalmış veya mantar ve çam kese böceği tarafından zarar görmüş olan bütün yaş sınıflarında bu böceğe rastlamak mümkündür. Bu böceğe karşı araştırma alanında her yıl Nisan ayından Kasım ayına kadar feromon mücadelesi yapılmaktadır (URL 2).

Hylurgus ligniperda(Fabricius, 1787): Hylurgus ligniperda böceği Coloptera takımının Scolytidae familyasındandır. Sekonder zararlı bir böcek. Özellikle çeşitli edafik ve klimatik problemler yüzünden ya da çeşitli mantar ve çam kese böceği tarafından zayıf düşmüş çam ağaçlarının kabuklarında veya açıkta bulunan kök kısımlarında zarar yapar. Bu böceğin varlığ 1 feromon tuzaklarına düşmesiyle fark edilmiştir. Feromon tuzaklarına Akdeniz Çam Kabuk Böceği miktarından çok daha az sayılarda düşmektedir (URL-3).

Hylurgus micklitzi (Wachtl, 1881): Hylurgus micklitzi böceği Coloptera takımının Scolytidae familyasındandır. Sekonder zararlı bir türdür. Yetişme ortamının bozuk olduğu kızılçam, karaçam, halep çamı ve fistık çamlarında zarar yapmaktadır (Sarıkaya ve Avc1, 2011).

\section{On İki Dişli Çam Kabuk Böceği (Ips} sexdentatus (Boerner, 1776)): On iki dişli çam kabuk böceği Coloptera takımını Scolytidae familyasındandır. Türkiye'de Picea orientalis'te epidemi yapmakta, bunun yanında çam (özellikle Pinus nigra, $P$. brutia ve $P$. sylvestris) ile göknar türlerinde de zarar yapmaktadır. Özellikle kabuğu kalın olan ağaçları tercih eder. İnce kabuklu ağaçlara da gitmektedir. Yumurta birakmak için hastalıklı, rüzgâr ve fırtına devriği, yanık alanlar, diğer böcekler tarafından tahrip edilmiş veya fizyolojik bakımdan zayıflamış ağaçları tercih eder. Sekonder zararlı bir böcek olmasına rağmen kolaylıkla çoğalarak primer zararlı bir vaziyet alır ve sağlıkl ağaçlara da zarar verir. Ağaçlara vermiş olduğu zarar ilk olarak tepe kısmında başladığı görülür. Ülkemiz ladin ormanlarında küçük gruplar halinde ağaçları kurutarak kapalılığın kırılmasına ve meşcere yapisının bozulmasina sebebiyet verir. Araştırma alanında diğer kabuk böcekleri kadar çok olmamakla beraber feromon tuzaklarına düştükleri görülmektedir (Bouhot ve ark, 1988).

Büyük Orman Bahçıvanı (Tomicus piniperda (L.)): Büyük Orman Bahçıvanı Coloptera takımının Scolytidae familyasındandır. Ülkemizde çam türlerinde zarar yapmaktadır. Ormancılığımız açısından önemli bir böcektir. Sekonder zararlılardandır. $\mathrm{Bu}$ yüzden sağlık durumları bozulmuş, dikili ağaçlarda zarar yapar. Olgunluk yiyimi yapmak amacıyla mayıs sürgünlerine giderek primer zarar oluşturur. Bu tür özellikle çeşitli tırtıllar tarafından zarar verilmiş çam türleri için çok tehlikeli olabilir. Araştırma alanında daha öncesinden çam kese böceği ve sürgün bükücüsü larvaları tarafından zarar uğratılmış ağaçlarda bu böceklere rastlanmıştır. $\mathrm{Bu}$ tür diğer kabuk böceklerinin aksine feromon üretmez. (Çanakçıŏlu ve Mol, 1998, Kennedy ve McCullough, 2012).

Tomicus destruens (Wollaston, 1865); Tomicus destruens Coloptera takımının Scolytidae familyasındandır. Pinus brutia, Pinus canariensis, Pinus halepensis, Pinus pinaster, Pinus pinea, Pinus radiata, Pinus sylvestris türlerinde zarar yapmaktadır. $\mathrm{Bu}$ tür ile büyük orman bahçıvanı morfolojik olarak birbirine çok benzemektedir. T.pinierda erken ilkbaharda, T. destruens ise sonbahar ile erken kış arası uçmaktadır. Bu türe özellikle Pinus pinea türleri üzerinde rastlanmaktadır (URL 4; Sarıkaya ve Avcı, 2010).

\section{Sahada Görülen Mantar Hastalıkları:}

2.2.1. Melampsora piniturqua (Çam Sürgün Bükücü Pası): Genç çam ağaçlarında görülen (özellikle 1-10 yaşlarında) bir mantar hastalığıdır. Sürgünlerin ilk büyüme başlangıcında 1-3 $\mathrm{cm}$ uzunluğunda sarı lekeler oluşur. Bu lekeler nedeniyle kabukta Haziran ayında çatlamalar görülür.

Kabuğun çatlaması sebebiyle desteğini kaybeden sürgün karşı taraftaki sürgün kısmının büyümesine devam etmesi sonucu aşağı doğru kıvrılır ve sarkık bir vaziyet alır. Daha sonra sürgün doğrularak yukarı doğru büyümesine davam eder fakat bu arada S şeklini almış olur. Bu arada birçok sürgün ölür ve ağaçların çalı formunda kalmasına sebep olur. Sahada birçok çam ağacında hastalığın tipik belirtisi olan S şeklinde sürgünler görülmektedir (Çanakçıŏlu ve Eliçin, 1998).

Diplodia pinea: Yetişme ortamı şartlarının kötü olduğu fazla gölgeye maruz kalma gibi durumların olduğu şatlarda görülen bir mantar hastalığı. Ağaçlandırma alanlarında bu hastalıktan egzotik türler daha fazla etkilenmektedir. 25 yaş üstü çamlar bu hastalıktan daha fazla etkilenmektedir. Her yaş grubunda çam ağaçları toprağın sıkı, fakir ve verimsiz, drenajın az olduğu ve kurak mıntıkalarda yapılmış ağaçlandırmalarda hastalıktan etkilenme oranı artmaktadır. Özellikle kökler çeşitli sebeplerle toprakta bulunan bazı kimyasal ve mekanik zararlardan etkilenmişse besin yetersizliğiyle beraber ağacın hastalığa karşı direnci düşmektedir (Günay, 2001). 


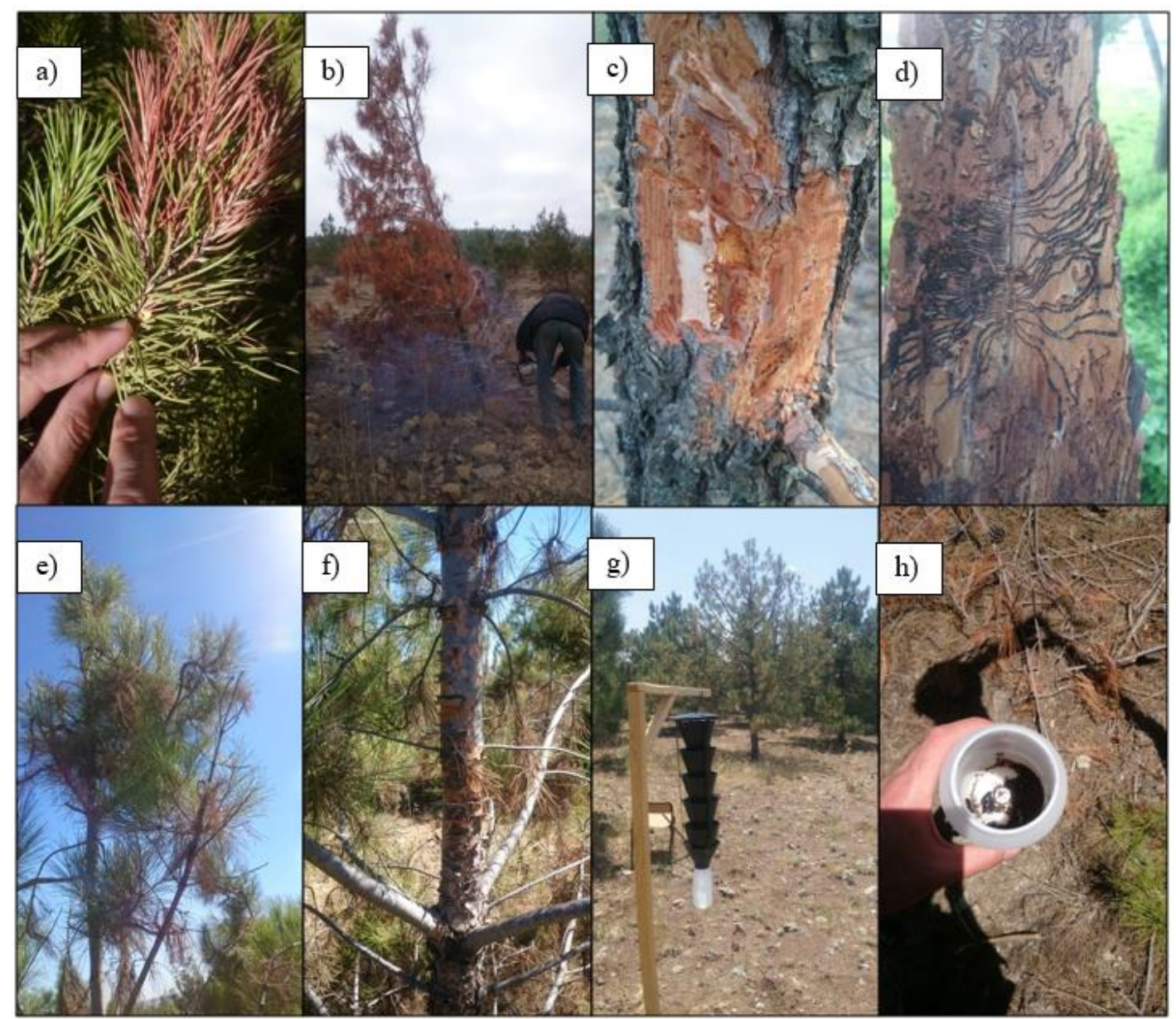

Şekil 3. Ağaçlandırma sahasında tespit edilen bazı zararlılar ve zararları (a= Tomicus piniperda-büyük orman bahçıvanı; b= kuruyan ağaçların alandan uzaklaştırılması; c= Orthotomicus erosus-Akdeniz çam kabuk böceği zararı; d= Akdeniz çam kabuk böceğinin larva yolları; e= Melampsora pinitorqua- sürgünlerin bükülmesi; f= kabuğu zarar gören kızıl çam ağacı; g= Araştırma alanındaki Feromon tuzakları; $h=$ tuzakta yakalanan böcekler).

Kahramanmaraş Elmalar Yeşil kuşak sahasında yapılan ağaçlandırma çalışmalarında yoğun olarak kullanılan Pinus brutia var. elderica dünya da birçok ağaçlandırma çalışmalarında kuraklığa dayanıklı olduğu gerekçesiyle kullanılmış bir türdür. Bu türün kullanıldığ $\breve{1}_{1}$ yerlerden birisi de Amerika Birleşik devletlerinin Texas Eyaletidir. 1960'l l yıllarda kuraklığa dayanıklı olduğu gerekçesiyle bu tür kullanılmış ve bunun sonunda birtakım böcek ve mantar hastalıklarıyla karşılaşılmıştır. Karşılaşılan bu zararlılar Rhyacionia neomexicana, Chionaspis pinifoliae, çeşitli kabuk böcekleri, Diplodea pinea, Phymatotrichopsis omnivora gibi mantar hastalıklarıdır (URL-5). Araştırma alanında görülen biyotik zararlılarla Amerika'da yapılan ağaçlandırma çalışmalarında görülen biyotik zararlılar arasında çok yakın benzerlikler olduğu görülmektedir. Araştırma alanında ileriki dönemlerde magnezyumun zehir etkisinden dolayı kökler gerekli besin maddelerini alamadığı için mantar ve böcek zararlarına karşı koyamamaktadır.
Topraklardaki $\quad \mathrm{Mg} \quad$ fazlalığı toprakların yararlanılabilir $\mathrm{Ca}$ miktarını ve bitkiler tarafindan alınabilir $\mathrm{K}$ miktarını olumsuz etkilemektedir. Toprakta Mg miktarının fazla oluşu zehir etkisine neden olduğu için $\mathrm{Ca}$ mineralinin bitkiler tarafindan alınımı engellemektedir (Proctor, 1971). K noksanlığı, bitkilerde büyüme geriliğine, çiçeklenmenin zayuflamasina ve yapraklarda sararmalara neden olurken, $\mathrm{Ca}$ noksanlığı da bitkilerin vejetasyon periyodu boyunca zayıf büyümesine ve hatta ölmesine neden olabilmektedir.

Ayrıca elde edilen verilere bakıldığında $\mathrm{P}$ eksikliği özellikle yaşlı yapraklarda sararma, kalın ve dik yaprak görünümü, bodur büyüme, mavimsi yeşil veya mor renk oluşumu gözlenmektedir.

\section{SONUCLLAR}

1. Günümüzde küresel ısınma, çevre ve hava kirliliği, erozyon, karbon salınımı gibi sorunlarla başa çıkabilmenin en önemli yollarından birisi 
ağaçlandırma çalışmalarıdır. $\mathrm{Bu}$ çalışmalar yapılırken ağaçlandırma etüt projelerinin çok iyi yapılması gerekmektedir. Bilhassa serpantinit toprakları kimyasal, fiziksel, hidro-fiziksel ve biyolojik özellikler bakımından uygun yetişme ortamı koşulları oluşturmadığı için bu alanlarda çok yönlü toprak ıslahı çalışması yapılmalıdır.

2. Çalışma sonucunda abiyotik zararlılardan toprak özelliklerinin ve iklim özelliklerin ağaçlandırma çalışmaları sonucu alana dikilen ağaçlarda olumsuz etklere neden oldukları, zayıf düşen ağaç türlerine sekonder zararlılar olan böcek ve mantarların yerleşerek popülasyonlarındaki artışa neden oldukları anlaşılmıştır.

3. Serpantin habitatlarının hassas alanlar olduğu göz önünde bulundurulduğunda, bu doğal alanlardaki biyotanın yoğunlaştırılması, çeşitlilik ve endemizm korunması farklı tür ağaçlandırmalarına karşın daha uygun olabilmektedir.

4. Serpantin anakayasina yapılacak ağaçlandırmalarda tür seçiminde serpantin sendromu sonucu ortaya çıkan kalsiyum eksikliğine, kuraklığa, zayıf toprak kalitesine, ağır metal fazlalığına ve güneşin etkisine karşı fenotip ve genotip bakımından toleransl bitki türlerinin seçilmesi ekolojik ve ekonomik açıdan oldukça önem arz etmektedir.

5. Ağaçlandırma yapılması düşünülen serpantin sahaları çıplak ve erozyona duyarlı alanlar olduğu için doğal erozyonu önlenmelidir. Bunu engellemek için 0-30 cm derinliğine kadar malçlama yöntemi ile toprak karıştırılarak ıslah edilme çalışmaları yapılabilir. Bu alanlara uygun türler seçilerek yeniden ağaçlandırılmalı ve ilk yıllar (fidan adaptasyonuna yardımcı olmak amacıyla) sulama ve gübreleme çalışmaları ile fidanlar desteklenebilir. Örneğin; Małek ve ark. (2011) ladin meşcerelerinde yaptıkları N, P ve K gübrelemeleri ile ölmekte olan ladin meşcerelerinin kurtarmıştır.

6. Orman ekosistemlerinin gelişimini ve sürdürülebilirliğinin sağlanması için toprak koşullarının bilinmesi ve sürekli izlenmesi gereklidir.

7. Serpantinler üzerinde yayılış gösteren bitkiler, özellikle de endemik bitkiler tüm dünyada taranmakta ve bu türlerin bazıları ekonomik değer taşımaktadır. Bu türler insanlar tarafından ağır metaller bakımından kirletilmiş alanların bu bitkiler tarafından temizlenmesi için kullanılmaktadır. Araştırma alanında gözlemlenen Silene, Alyssum, Thlaspi, Cochleraia gibi türler nikel akümülatörü olarak bilinirler ve yapılan araştırmalarda bu türler üzerinde nikel içeriğinin \%2'yi geçtiği bulunmuştur (Avcı, 2005). Araştırma alanının yukarıda açıklanan duruma göre bu bitkiler bakımından taranması ve araştırılması gerekmektedir.

8. Bu sahalar üzerinde ekstrem toprak koşullarına karşı genetik çözümler üretmiş bazı bitkiler yaşama imkanı bulmuştur. $\mathrm{Bu}$ bakımdan bu alanlar endemik türler bakımından zengindir. Aynı zamanda bu alanlar biyolojik çeşitlilik açısından önemlidir. Son yapılan araştırmalara göre Serpantin habitatlara özgü takson sayısı 248 olarak bulunmuş ve bu sayının daha da artacağı tahmin edilmektedir (Özdeniz ve ark., 2017). Yine bu alanlarda yüksek oranda nikel biriktiren bitkiler üzerinde beslenen böceklerin de tespit edilmesi gerekmektedir. Ortaya çok sayıda endemik böcek türlerinin çıkacağı düşünülmektedir. Küba ve Amerika'da yapılan araştırmalarda bu özel habitatlarda bulunan böceklerin üzerinde yüksek oranda nikel bulunduğu tespit edilmiştir (Rascio ve NavariIzzo, 2011). Serpantinit içeren alanların dar bir görüşle ağaçlandırılması yanlıştır.

9. Araştırma alanında eskiden kalma çok sayıda Quercus coccifera türlerine rastlanmıştır. Yapılan literatür taramasında serpantinit alanlarda sert yapraklı türlerin bu alanlarda daha iyi yetiştiği belirtilmektedir. Bu yüzden serpantinit alanlarda ağaçlandırma çalışmalarında sert yapraklı türlere ağırlık verilmesi gerekliliği çalışma sonucunda tespit edilmiştir.

\section{TEŞEKKÜR}

Kabuk böceklerinin teşhisinde Süleyman Demirel Üniversitesi, Orman Fakültesi Orman Entomolojisi ve Koruma Anabilim Dalından Doç. Dr. Oğuzhan SARIKAYA'ya ve OGM Orman Zararlıları ile Mücadele Şube Müdürü biyolog Yaşar AKSU ya, Anakaya teşhisi için Kahramanmaraş Sütçü İmam Üniversitesi, Jeoloji Mühendisliği Dr. Öğretim Üyesi Tamer RIZAOĞLU'na teşekkür ederiz.

\section{KAYNAKLAR}

Anonim 1992. Orman Genel Müdürlüğü. Yeşil Kuşak Ağaçlandırma Çalışmaları, Tamim No:10.

Anonim 1994. Npag Data: Hylurgus Ligniperda RedHaired Bark Beetle. https://pestalert.org/storage/H_ligniperda_ds94.pdf

Anonim 2004. Orthotomicus erosus. http://www.fao.org/docrep/011/i0640e/i0640e10r.pdf

Anonim 2011. Tomicus destruens. https://wiki.bugwood.org/Tomicus_destruens

Avcı M 2005. Çeşitlilik Ve Endemizm Açısından Türkiye'nin Bitki Örtüsü. İstanbul Üniversitesi Edebiyat Fakültesi Dergisi, 13:27-55.

Blake GR 1965. Particle density. In: Methods of Soil Analysis, Part 1. Physical and Mineralogical Methods, ed. A Klute, Agronomy Monograph 9, American Society of Agronomy-Soil Science Society of America, Madison, Wisconsin, USA, pp. 371-373. 
Brearley F 2005. Nutrient limitation in a Malaysian ultramafic soil. Journal of Tropical Forest Science, 17(4): 596-609.

Bouhot L, Lieutier F, Debouzie D 1988. Spatial and temporal distribution of attacks by Tomicus piniperda L. and Ips sexdentatus Boern. (Col., Scolytidae) on Pinus sylvestris. Journal of Applied Entomology, 106 (1-5): 356-371.

Bouyoucos GJ 1962. Hydrometer method improved for making particle size analyses of soils. Agronomy Journal, 54: 464-465.

Brooks RR 1987. In Serpentine and Its Vegetation, ed. TR Dudley. Portland, OR: Dioscorides. 454 pp.

Brooks RR, Yang XH 1984. Elemental levels and relationships in the endemic serpentine flora of the Great Dyke, Zimbabwe and their significance as controlling factors for this flora. Taxon, 33:392-99

Çanakçıŏ̆lu H, Eliçin G 1998. Fitopatoloji Özel Bölüm. İstanbul Üniversitesi Orman Fakültesi Yayınları, Yayın No:456, İstanbul, 322s.

Çanakçıŏlu H, Mol T 1998. Orman Entomolojisi, Zararlı ve Yararlı Böcekler. İstanbul Üniversitesi Orman Fakültesi Yayınları, İstanbul, 542s.

Günay İ 2001. Çamlarda Dilodia (Diplodia pinea Desm.) Hastalığı. Doğu Akdeniz Ormancılık Araştırma Müdürlüğü, DOA DERGISİ (Journal of DOA), 7: 1-12.

Hizalan E, Ünal H 1965. Topraklarda önemli kimyasal analizler. Ankara Üniversitesi Ziraat Fakültesi, Yayın No:278, Ankara, Yrd. Ders Kitabı No:97.

Hoover GA 2004. European Pine Shoot Moth. Entomological Notes Department of Entomology, College of Agricultural Sciences. https://ento.psu.edu/extension/factsheets/pdf/euPineS hootMoth.pdf

Janzen HH 2004. Carbon cycling in earth systems-a soil science perspective. Agriculture, Ecosystems and Environment, 104:399-417.

Jenny H 1980. The Soil Resource: Origin and Behavior. Ecol. Stud. 37:256-59. New York: Springer-Verlag. $377 \mathrm{pp}$.

Kennedy AA, McCullough DG 2012. Phenology of the Larger European Pine Shoot Beetle Tomicus piniperda (L.) (Coleoptera: Scolytidae) in Relation to Native Bark Beetles and Natural Enemies in Pine Stands. Environmental Entomology, 31(2): 261-272.

Krause W 1958. Andere Bodenspezialisten. In Handbuch der Pflanzenphysiologie, ed. G Michael, Berlin: Springer-Verlag, 4:758-806.

Kruckeberg AR 1954. The ecology of serpentine soils: A symposium. III. Plant species in relation to serpentine soils. Ecology 35:267- 74.

Kruckeberg AR 1985. California Serpentines:Flora, Vegetation, Geology, Soils, and Management Problems. Berkeley: Univ. Calif. Press. 180 pp.

Kruckeberg AR 2002. The influences of lithology on plant life. In Geology and Plant Life; The Effects of Landforms and Rock Type on Plants, Seattle/London: Univ. Wash. Press. 362 pp.
Loew O, May DW 1901. The relation of lime and magnesia to plant growth. U.S. Dep. Agric. Bur. Plant Ind. Bull. 1:1-53

Małek S, Januszek K, Barszcz J, Błońska E, Wanic T, Gasienica-Fronek W, Kroczek M 2011. Preliminary assessment of the ecochemical condition of soils after fertilization of younger spruce Picea abies (L.) H. Karst. stands in the Beskid Ślaski and Żywiecki Mts. Folia Forestalia Polonica, A, 53(2): 93-104.

Marrs RH, Proctor J 1976. The response of serpentine and nonserpentine Agrostis stolonifera L. to magnesium and calcium. Journal of Ecology, 64:95364

Moody JB 1976. Serpentinization: a review. Lithos, 9:125-138.

O'Hanley DS 1996. Serpentinites: Records of Tectonic and Petrological History. New York: Oxford University Press.

Özdeniz E, Özbey BG, Kurt L, Bölükbaşı A 2017. Serpantin Ekolojisi ve Türkiye Serpantin Florası'na Katkılar. Toprak Bilimi ve Bitki Besleme Dergisi, 5 (1): $22-33$.

Proctor J 1970. Magnesium as a toxic element. Nature, 227:742-43

Proctor J 1971. The plant ecology of serpentine. II. Plant responses to serpentine soils. Journal of Ecology, 59:397-410.

Proctor J, Woodell SRJ 1975. The ecology of serpentine soils. Advance Ecological Research, 9:255- 365.

Proctor J 2003. Vegetation and soil and plant chemistry on ultramafic rocks in the tropical Far East. Perspectives in Plant Ecology, Evolution and Systematics, 6(1-2): 105-124.

Rascio N, Navari-Izzo F 2011. Heavy metal hyperaccumulating plants: How and why do they do it? And what makes them so interesting? Plant Science, 180(2): 169-181.

Ritter-Studni cka H 1968. Die serpentinomorphosen der flora bosniens. Bot. Jahrb. 88: 443-65.

Sarıkaya O, Avcı M 2010. Distribution and biology of the Mediterranean Pine Shoot Beetle Tomicus destruens (Wollaston, 1865) in the Western Mediterranean region of Turkey. Türk. Entomol. Dergisi, 34 (3): 289298.

Sarıkaya O, Avcı M 2011. Bark beetle fauna (Coleoptera: Scolytinae) of the coniferous forests in the Mediterranean region of Western Turkey, with a new record for Turkish fauna. Turk J Zool, 35(1): 33-47.

Şahin K, Avcıŏ̆lu B 2017. Türkiye Çölleşme Risk Modeli. 2023’e Doğru 4.Doğa ve Ormancılık Sempozyumu Bildiri Kitabı. TMMOB Orman Mühendisleri Odası, 3-6 Aralık, Antalya.

URL1.https://services.countyofnapa.org/AgendaNet/Dow nloadDocument.aspx?type=BOS\&doctype=ATTACH MENT\&id=30584

Ülgen N, Ateşalp M 1972. Toprakta Bitki Tarafindan Alınabilir Fosfor Tayini, Köy İşleri Bakanlığı, Topraksu Genel Müdürlüğü, Toprak ve Gübre 
Araştırma Enstitüsü, Teknik Yayınlar Serisi, Sayı 21, Ankara, $17 \mathrm{~s}$.

Walker RB 1948. A study of serpentine soil infertility with special reference to edaphic endemism. Univ. Calif., Berkeley, $\mathrm{PhD}$ thesis, $101 \mathrm{pp}$.

Walker RB 1954. The ecology of serpentine soils: A symposium. II. Factors affecting plant growth on serpentine soils. Ecology, 35:259-66.

Walker RB, Walker HM, Ashworth PR 1955. Calciummagnesium nutrition with special reference to serpentine soils. Plant Physiol. 30:214-21
Walkley A, Black A 1934. An examination of the Degtjareff method for determining soil organic matter, and proposed modification of the chromic acid titration method. Soil Science, 37: 29-38.

Yaşar, B., Küçükçakal, Ü. 2013 Isparta ili park ve süs bitkilerinde zararlı Diaspididae (Hemiptera: Coccoidea) türleri. Türk. Entomol. Bült., 3 (3):161168. 